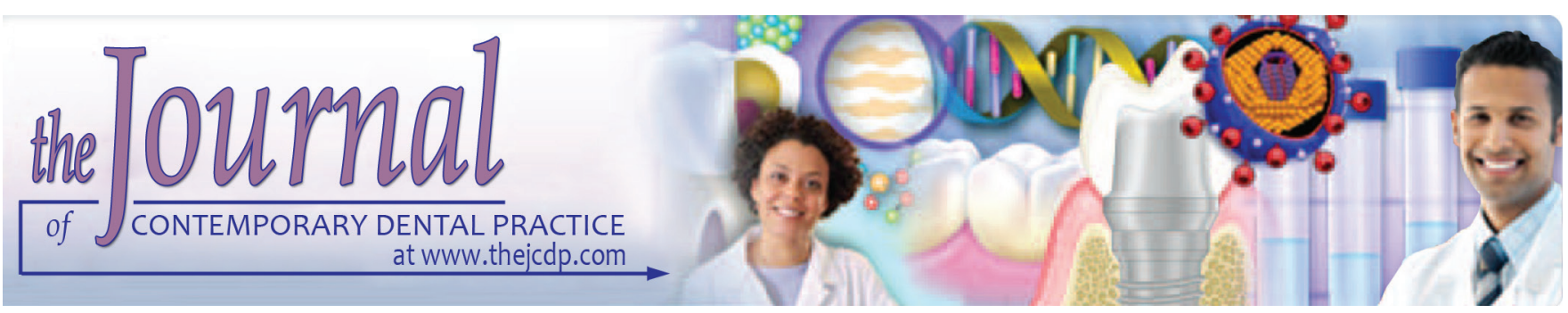

\title{
Denture Hygiene Knowledge and Practices among Complete Denture Wearers attending a Postgraduate Dental Institute
}

\author{
${ }^{1}$ Thatapudi Shankar, ${ }^{2}$ Snigdha Gowd, ${ }^{3}$ Vinay Suresan, ${ }^{4}$ Sneha Mantri, ${ }^{5}$ Sudhanshu Saxena \\ ${ }^{6}$ Prateek Mishra, ${ }^{7}$ Pragya Panday
}

\begin{abstract}
Aims: The aim of this study was to assess the denture hygiene knowledge and practices among patients using complete dentures attending a postgraduate dental hospital in Jabalpur city. The objective of this study was to assess the relationship between hygiene knowledge and practices to the denture wearer's gender, education, and income.
\end{abstract}

Materials and methods: A descriptive, cross-sectional survey was conducted using a self-administered questionnaire involving the complete denture patients attending the Department of Prosthodontics. The study subjects were randomly selected by recruiting old dentures wearers visiting the Department of Prosthodontics for a recall visit or for new dentures on the odd dates of the month. All subjects signed an informed consent before filling the questionnaire. The institutional review committee approved the study. Descriptive statistics included computation of frequencies and percentages. Nonparametric test, namely, chi-square test, was used for further data analysis; p-value $<0.05$ was considered statistically significant.

${ }^{1}$ Department of Prosthodontics, Kalinga Institute of Dental Sciences, KIIT University, Bhubaneswar, Odisha, India

${ }^{2}$ Department of Dento-facial Orthopaedics and Orthodontics Kalinga Institute of Dental Sciences, KIIT University, Bhubaneswar Odisha, India

${ }^{3}$ Department of Public Health Dentistry, Kalinga Institute of Dental Sciences, KIIT University, Bhubaneswar, Odisha, India

${ }^{4,6}$ Department of Prosthodontics, Hitkarini Dental College \& Hospital, Jabalpur, Madhya Prades, India

${ }^{5}$ Department of Public Health Dentistry, Hazaribagh Dental College \& Hospital, Hazaribagh, Jharkhand, India

${ }^{7}$ Department of Prosthodontics, Guru Gobind Singh College \& Hospital, Bhuranpur, Madhya Pradesh, India

Corresponding Author: Vinay Suresan, Department of Public Health Dentistry, Kalinga Institute of Dental Sciences, KIIT University, Bhubaneswar, Odisha, India, Phone: +918763799695 e-mail: reachvinays@yahoo.co.in
Results: A total of 530 individuals were approached for participation in our survey, $30(5.66 \%)$ subjects declined to participate. The results showed that 195 (39\%) subjects were wearing the same dentures for more than 5 years. In this study, 51 (10.2\%) subjects reported never having been advised by their dentists as to how to clean their dentures. Among all the subjects interviewed, $264(52.8 \%)$ reported to clean the oral tissues daily. This study disclosed that $66(13.2 \%)$ of the subjects usually slept with their dentures. Maximum subjects in illiterate group had experienced bad breath sometimes when compared with subjects in postgraduate group $\left(\chi^{2}=47.452, p<0.001\right)$. There was a significant difference for method of denture cleaning according to gender $\left(\chi^{2}=101.076, p<0.001\right)$.

Conclusion: The majority of the denture wearers have limited knowledge of denture cleansing and oral hygiene practices. Hygiene habits and practices may not always present a positive correlation with the gender, educational level, and income of the subjects.

Clinical significance: Periodic recall for evaluation of denture and mucosal surfaces along with reinforcement of denture hygiene instructions will go a long way in helping the patients reap maximum benefits out of their prostheses.

Keywords: Complete dentures, Denture cleanser, Denture hygiene, Edentulous, Overnight wearing.

How to cite this article: Shankar T, Gowd S, Suresan V, Mantri S, Saxena S, Mishra P, Panday P. Denture Hygiene Knowledge and Practices among Complete Denture Wearers attending a Postgraduate Dental Institute. J Contemp Dent Pract 2017;18(8):714-721.

Source of support: Nil

Conflict of interest: None

\section{INTRODUCTION}

Over the past few decades, the life expectancy in both developing and developed countries has increased. Correspondingly, the proportion of the elderly among the total population has also increased. There are 600 million 
people aged 60 years and above, and this number will double by 2025. By the year 2050, there will be 2 billion people and $80 \%$ of them aged 60 years and above living in developing countries. ${ }^{1}$ Aligned with this increase, the oral health status of the elderly also has gained importance. Tooth loss in adult population increases with age as does the additive factors leading to this over time. For this reason, the rates of complete tooth loss are customarily the highest in the oldest age groups. Despite several efforts by dentists aimed at conservation of teeth, a considerable number of patients still lose their teeth to dental caries, periodontal diseases, tooth wear lesions, trauma, and tumors of the jaws. $^{2}$ The number of individuals requiring dentures has increased with the aging population. ${ }^{3-5}$ Complete dentures are the most common treatment for total loss of teeth in a dental arch. Similarly, the most common teeth replacement for partial loss of tooth is removable partial denture. ${ }^{6,7}$

From the moment the edentulous patient is fitted with dentures, the important phase of oral and denture aftercare begins. Clinical follow-up should include instructing patients on denture care, guidance regarding features of an ill-fitting denture, rebasing procedures, and the need for replacing dentures after some years. Regular oral and denture hygiene procedures play a major role in the maintenance of oral health and the long-term success of removable prosthodontic treatment. ${ }^{8}$ Rehabilitative treatment is successful only when patients are highly motivated toward the correct method of use and hygiene maintenance procedures. It is reported that the quality of the denture fitting surface, occlusal relations, denture age, and hygiene are important factors contributing to the prevalence of oral mucosal lesions associated with denture use. ${ }^{9}$

Care of dentures and the mucosal tissues of the edentulous mouth can be important for overall health, especially in the elderly. Surveys show that many patients fail to keep their dentures clean and prefer to use dirty dentures. This situation may be a result of negligence of clinicians in recalling their denture patients and reinforcing the denture hygiene methods. ${ }^{10}$ Regular cleaning of dentures is recognized as an important part of oral hygiene for denture wearers. Dentures predispose the wearer to denture stomatitis, ${ }^{11}$ harbors many potential pathogens, ${ }^{12}$ causing microorganisms. Unclean dentures result in oral mucosal diseases, impairment in eating, and fall in self-esteem on a frail elder than on a younger, healthier person. ${ }^{13,14}$ Ineffective denture cleaning may also lead to esthetic problems, such as staining or bad breath. Denture wearers often suffer from the anxiety of further oral care problems. Furthermore, denture wearers fear that the esthetic problems of denture malodor and staining may reveal denture wearing to others. ${ }^{15}$

A number of studies have reported various methods employed by denture wearers to clean dentures. These methods range from the simplest method being brushing with water and toothpaste which is considered routine to complex methods, such as use of chemical solutions and tablets. ${ }^{16-18}$ Another study related awareness of denture cleaning to socioeconomic status and disease, ${ }^{19}$ while variations were also found by sex, with women found to clean their dentures more than men. ${ }^{20}$ However, in general, a lack of knowledge was often found among all these patients, ${ }^{21}$ with a general understanding that "I should do something", but with methods being variable. $^{22}$ Often, patients reported never having been instructed by their dentists as to how to clean their dentures. ${ }^{23}$ However, surveys have reported that complete denture wearers have difficulty in cleaning their dentures ${ }^{24,25}$ and so periodic recall programs are effective in promoting good oral health. It is often noted that patients do not report to the dentist for reinforcement of denture cleansing instructions and the maintenance of their dentures at appropriate intervals. ${ }^{26}$ It is the responsibility of the dentist to recall and educate their patients periodically.

The difference in oral hygiene habits and attitudes may be related to number of factors, such as education, gender, social status, or age. ${ }^{27}$ The need for geriatric oral health care will increase several fold in the coming years. The success of oral health care of the elderly is determined by various factors, such as physical, mental, socioeconomic, and family background of the elderly, their chronic illnesses and drug treatment, and age-related disabilities. There is a need for a separate specialization in the care of elderly. Hence, the need for geriatric dentistry arises. ${ }^{28}$

Using a specific questionnaire, the aim of this study was to assess the denture hygiene knowledge and practices among patients using complete dentures attending a postgraduate dental hospital in Jabalpur city. The objective of this study was to assess the relationship between hygiene knowledge and practices to the denture wearer's gender, education, and income.

\section{MATERIALS AND METHODS}

A descriptive, cross-sectional survey was conducted using a self-administered questionnaire involving the complete denture patients attending the Department of Prosthodontics, postgraduate dental hospital in Jabalpur city.

A comprehensive close-ended, intervieweradministered questionnaire comprising 17 questions was designed. The questionnaire recorded their demographic information, such as level of education, monthly income, and questions related to denture age, nocturnal denture wearing habits, instructions received from their dentist, oral and denture hygiene protocol followed by them, and their recall visits. A questionnaire was available both in 
English and Hindi languages to ensure linguistic validity. This questionnaire was mailed to 10 experts in this field to review it for its face and construct validity. The experts were requested to identify the deficient areas and provide recommendations and suggestions on ways to improve the clarity of the questions. After the necessary modifications, the Cronbach's alpha agreement among the experts was $82 \%$ or 0.82 , which denotes a high level of agreement.

The questionnaire was pilot tested on 30 patients and was assessed for the uniformity of interpretation. The questionnaire took about 15 minutes to complete. The data gathered during the pilot study were not included in the main study. Based on the response rate in the pilot study, which was $87 \%$, a confidence interval of $95 \%$, and absolute precision set at $3 \%$ the sample size calculated was 483. The minimum sample size was increased by $10 \%$ to compensate for nonresponse and incomplete responses, bringing the total sample size to 530 .

The study subjects were randomly selected by recruiting old dentures wearers visiting the Department of Prosthodontics for a recall visit or for new dentures on the odd dates of the month. These patients were personally approached by the investigators and the nature and the purpose of the study was explained. The willing subjects were requested to complete a comprehensive closedended, self-administered questionnaire. All subjects signed an informed consent before filling the questionnaire. The subjects were asked not to reveal their identity. The institutional review committee approved the study.

Descriptive statistics included computation of frequencies and percentages. Nonparametric test, namely, chi-square test, was used for further data analysis; $\mathrm{p}<0.05$ was considered statistically significant. Data analysis was performed using Statistical Package for the Social Sciences version 21 for Windows. ${ }^{29}$

\section{RESULTS}

A total of 530 individuals were approached for participation in our survey, 30 (5.66\%) subjects declined to participate. Hence, response rate was $94.34 \%$. Out of 500 study subjects, 261 (52.2\%) were males and 239 (47.8\%) were females. Age distribution showed that 37 (7.4\%) subjects were below 50 years, $220(44.0 \%)$ subjects were between 50 and 65 years, and 243 (48.6\%) subjects were more than 65 years. Education wise, 51 (10.2\%) subjects were illiterate, $161(32.2 \%)$ were educated till primary level, 147 (29.4\%) secondary level, 130 (26.0\%) graduation, and $11(2.2 \%)$ postgraduation level. Maximum subjects $(420,84 \%)$ were having a monthly income below Rs. 10,000, 37 (7.4\%) between Rs. 10,000 and 20,000, and 43 (8.6\%) more than Rs. 20,000. A total of 173 (34.6\%) subjects were wearing the denture for $<3$ years, 132 (26.4\%) for 3 to 5 years, and 195 (39.0\%) for more than 5 years.
The results showed that 195 (39\%) subjects were wearing the same dentures for more than 5 years. In this study, 51 (10.2\%) subjects reported never having been advised by their dentists as to how to clean their dentures. Nearly half of the study population (229, $45.8 \%$ ) brushed with water to clean their dentures. With regard to the frequency of denture cleaning, 102 (20.4\%) of the study population cleaned their dentures at least once a day, $266(53.2 \%)$ subjects cleaned twice a day, $63(12.6 \%)$ subjects cleaned thrice daily, and 69 (13.8\%) subjects cleaned more than thrice daily. Among all the subjects interviewed, 264 (52.8\%) reported to clean the oral tissues daily; the most frequently brushed region was the tongue and the palate. Oral rinse was the most common adjunct to brushing among, 145 (29.0\%) subjects. This study disclosed that $66(13.2 \%)$ of the subjects usually slept with their dentures.

Subjects' denture hygiene knowledge and practices across various educational levels are presented in Table 1. Maximum subjects in all the education groups told that dentures should be immersed in plain water once removed from the oral cavity. The majority of the subjects among illiterate (45.1\%) and secondary education level (55.1\%) said that they did not know whether unhygienic dentures could be a source of oral infection. Maximum subjects in illiterate group had experienced bad breath sometimes, whereas maximum subjects in postgraduate group had never experienced bad breath. Chi-square test showed significant difference between the groups $\left(\chi^{2}=47.452, \mathrm{p}<0.001\right)$.

Table 2 shows the subjects' denture hygiene knowledge and practices across gender. There was significant difference between males and females for time of denture wearing $\left(\chi^{2}=14.648, \mathrm{p}<0.01\right)$ and also the medium of storage of denture $\left(\chi^{2}=13.440, \mathrm{p}=0.004\right)$. Yet again, no statistically significant difference was observed for the duration of wearing dentures and the medium used for the delivery of denture care instructions. Among females, 65 (27.2\%) were using only water for denture cleaning compared with 19 (7.3\%) males. Immersion of commercial denture cleaner was used by 46 (17.6\%) males and only 11 (4.6\%) females (Graph 1). Chi-square test showed significant difference for method of denture cleaning according to gender $\left(\chi^{2}=101.076, \mathrm{p}<0.001\right)$. The frequency of changing brush within 3 to 6 months and more than 6 months was $57(34.8 \%)$ and $59(36.0 \%)$ among males. Among females out of 85 denture cleaning brush user maximum $(63.5 \%)$ were changing it within $<3$ months $\left(\chi^{2}=62.280, \mathrm{p}<0.001\right)$.

Subjects' denture hygiene knowledge and practices across monthly income groups are presented in Table 3. All the subjects in more than Rs. 20,000 monthly income group reported that dentist/dental assistant had given denture cleansing instruction. This proportion decreased 
Denture Hygiene Knowledge and Practices among Complete Denture Wearers

Table 1: Subjects' denture hygiene knowledge and practices across educational background $(n=500)$

\begin{tabular}{|c|c|c|c|c|c|c|c|}
\hline \multicolumn{2}{|c|}{ Variables } & \multicolumn{5}{|c|}{ Education level $n(\%)$} & \multirow[b]{2}{*}{$p$-value } \\
\hline Questions & Options & Illiterate & $\begin{array}{l}\text { Primary } \\
\text { level }\end{array}$ & $\begin{array}{l}\text { Secondary } \\
\text { level }\end{array}$ & Graduation & Postgraduation & \\
\hline \multirow{4}{*}{$\begin{array}{l}\text { Storage of denture after } \\
\text { removal from oral cavity }\end{array}$} & Wrap in cloth & 09 (17.6) & $29(18.0)$ & $58(39.5)$ & $32(24.6)$ & $00(0.0)$ & \multirow{4}{*}{$\begin{array}{l}\chi^{2}=103.719 \\
p=0.000 \\
\text { Significant } \\
\text { different }\end{array}$} \\
\hline & Immerse in plain water & $32(62.7)$ & $103(64.0)$ & $85(57.8)$ & $93(71.5)$ & $11(100.0)$ & \\
\hline & Wrap in a plastic bag & $00(0.0)$ & $25(15.5)$ & $04(2.7)$ & $03(2.3)$ & $00(0.0)$ & \\
\hline & Leave it out in the open & $10(19.6)$ & $04(2.5)$ & $00(0.0)$ & $02(1.5)$ & $00(0.0)$ & \\
\hline \multirow{3}{*}{$\begin{array}{l}\text { Are unhygienic dentures } \\
\text { a source of infection? }\end{array}$} & Yes & 19 (37.3) & $89(55.3)$ & $59(40.1)$ & $84(64.6)$ & $11(100.0)$ & \multirow{3}{*}{$\begin{array}{l}\chi^{2}=96.427 \\
p=0.000 \\
\text { Significant } \\
\text { different }\end{array}$} \\
\hline & No & $09(17.6)$ & $46(28.6)$ & $07(4.8)$ & $09(6.9)$ & $00(0.0)$ & \\
\hline & Do not know & $23(45.1)$ & $26(16.1)$ & $81(55.1)$ & $37(28.5)$ & $00(0.0)$ & \\
\hline \multirow{4}{*}{$\begin{array}{l}\text { Frequency of denture } \\
\text { cleaning per day }\end{array}$} & Once & $08(15.7)$ & $30(18.6)$ & $31(21.1)$ & $33(25.4)$ & $00(0.0)$ & \multirow{4}{*}{$\begin{array}{l}\chi^{2}=27.487 \\
p=0.007 \\
\text { Significant } \\
\text { different }\end{array}$} \\
\hline & Twice & $30(58.8)$ & $75(46.6)$ & $82(55.8)$ & $72(55.4)$ & $07(63.6)$ & \\
\hline & Thrice & $07(13.7)$ & $21(13.0)$ & $14(9.5)$ & $17(13.1)$ & $04(36.4)$ & \\
\hline & More than thrice & $06(11.8)$ & $35(21.7)$ & $20(13.6)$ & $08(6.2)$ & $00(0.0)$ & \\
\hline \multirow{3}{*}{$\begin{array}{l}\text { Do you experience bad } \\
\text { smell/halitosis with your } \\
\text { dentures? }\end{array}$} & Yes & 09 (17.6) & $04(2.5)$ & $32(21.8)$ & $16(12.3)$ & $00(0.00)$ & \multirow{3}{*}{$\begin{array}{l}\chi^{2}=47.452 \\
p=0.000 \\
\text { Significant } \\
\text { different }\end{array}$} \\
\hline & Sometimes & $35(68.6)$ & $78(48.4)$ & $58(39.5)$ & $66(50.8)$ & $04(36.4)$ & \\
\hline & Never & 07 (13.7) & $79(49.1)$ & $57(38.8)$ & $48(36.9)$ & 07 (63.6) & \\
\hline
\end{tabular}

Table 2: Subjects' denture hygiene knowledge and practices across gender $(n=500)$

\begin{tabular}{|c|c|c|c|c|}
\hline \multicolumn{2}{|l|}{ Variables } & \multicolumn{2}{|c|}{ Gender } & \multirow[b]{2}{*}{ p-value } \\
\hline Practice questions & Options & Male & Female & \\
\hline \multirow[t]{3}{*}{ Duration of denture wearing } & $<3$ years & $85(32.6)$ & $88(36.8)$ & \multirow{3}{*}{$\begin{array}{l}\chi^{2}=1.192, p=0.551 \\
\text { Not significant }\end{array}$} \\
\hline & $3-5$ years & $73(28.0)$ & $59(24.7)$ & \\
\hline & $>5$ years & $103(39.5)$ & $92(38.5)$ & \\
\hline \multirow[t]{4}{*}{ Time of denture wearing } & Only during eating & $73(28.0)$ & $59(24.7)$ & \multirow{4}{*}{$\begin{array}{l}\chi^{2}=14.648, p=0.002 \\
\text { Significant different }\end{array}$} \\
\hline & All day except eating & $103(39.5)$ & $92(38.5)$ & \\
\hline & All day during eating & $128(49.0)$ & $92(38.5)$ & \\
\hline & Day and night & $42(16.1)$ & $24(10.0)$ & \\
\hline \multirow[t]{4}{*}{ Storage of denture } & Wrap in a cloth & $63(24.1)$ & $65(27.2)$ & \multirow{4}{*}{$\begin{array}{l}\chi^{2}=13.440, p=0.004 \\
\text { Significant different }\end{array}$} \\
\hline & Immerse in plain water & $184(70.5)$ & $140(58.6)$ & \\
\hline & Wrap in plastic bag & $09(3.4)$ & $23(9.6)$ & \\
\hline & Leave the denture out in air & $05(1.9)$ & $11(4.6)$ & \\
\hline \multirow[t]{3}{*}{ Medium used for denture cleansing instruction } & Verbal & $140(76.1)$ & $116(75.3)$ & \multirow{3}{*}{$\begin{array}{l}\chi^{2}=0.028, p=0.986 \\
\text { Not significant }\end{array}$} \\
\hline & Written & $21(11.4)$ & $18(11.7)$ & \\
\hline & Practical demonstrations & $23(12.5)$ & $20(13.0)$ & \\
\hline \multirow[t]{4}{*}{ Denture cleansing in a day } & Once & $21(8.0)$ & $81(33.9)$ & \multirow{4}{*}{$\begin{array}{l}\chi^{2}=56.302, p=0.000 \\
\text { Significant different }\end{array}$} \\
\hline & Twice & $159(60.9)$ & $107(44.8)$ & \\
\hline & Thrice & $45(17.2)$ & $18(7.5)$ & \\
\hline & More than three times & $36(13.8)$ & $33(13.8)$ & \\
\hline
\end{tabular}

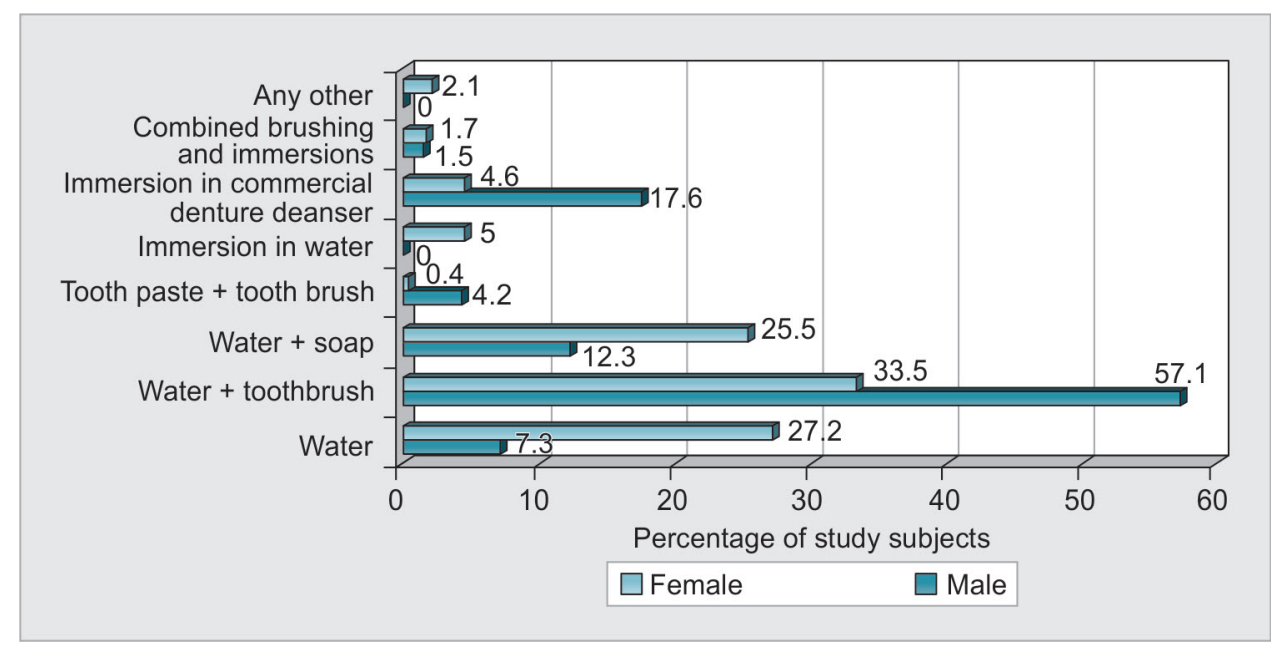

Graph 1: Subjects' denture cleansing practices across gender $(n=500)$ 
Table 3: Subjects' denture hygiene knowledge and practices across monthly income groups $(n=500)$

\begin{tabular}{|c|c|c|c|c|c|}
\hline \multicolumn{2}{|l|}{ Variables } & \multicolumn{3}{|c|}{ Monthly income (Rupees) } & \multirow[b]{2}{*}{$p$-value } \\
\hline Practice questions & Options & $<10,000$ & $10,000-20,000$ & $>20,000$ & \\
\hline \multirow{3}{*}{$\begin{array}{l}\text { Whether dentist/dental assistant had } \\
\text { given denture cleansing instruction }\end{array}$} & Yes & $261(62.1)$ & $34(91.9)$ & $43(100.0)$ & \multirow{3}{*}{$\begin{array}{l}\chi^{2}=36.290 \\
p=0.000 \text { Significant } \\
\text { different }\end{array}$} \\
\hline & No & $50(11.9)$ & $01(2.7)$ & $00(0.0)$ & \\
\hline & Do not know & $109(26.0)$ & $02(5.4)$ & $00(0.0)$ & \\
\hline \multirow{4}{*}{$\begin{array}{l}\text { When do you have to replace your } \\
\text { old dentures? }\end{array}$} & $<3$ years & $103(24.5)$ & $04(10.8)$ & $00(0.0)$ & \multirow{4}{*}{$\begin{array}{l}\chi^{2}=34.748 \\
p=0.000 \text { Significant } \\
\text { different }\end{array}$} \\
\hline & $3-5$ years & $100(23.8)$ & $08(21.6)$ & $09(20.9)$ & \\
\hline & $>5$ years & $119(28.3)$ & $05(13.5)$ & $21(48.8)$ & \\
\hline & Only if broken/ill-fitting & $98(23.3)$ & $20(54.1)$ & $13(30.2)$ & \\
\hline \multirow[t]{3}{*}{ Do you use oral rinse? } & Daily & $130(31.0)$ & $10(27.0)$ & $05(11.6)$ & \multirow{3}{*}{$\begin{array}{l}\chi^{2}=12.895 \\
p=0.012 \text { Significant } \\
\text { different }\end{array}$} \\
\hline & Sometimes & $128(30.5)$ & $13(35.1)$ & $10(23.3)$ & \\
\hline & Never & $162(38.6)$ & $14(37.8)$ & $28(65.1)$ & \\
\hline \multirow{4}{*}{$\begin{array}{l}\text { When did you last visit your dentist } \\
\text { for your denture check-up? }\end{array}$} & $<6$ months & $140(33.3)$ & $23(62.2)$ & $00(0.0)$ & \multirow{4}{*}{$\begin{array}{l}\chi^{2}=38.716 \\
p=0.000 \text { Significant } \\
\text { different }\end{array}$} \\
\hline & 6-12 months & $120(28.6)$ & $09(24.3)$ & $15(34.9)$ & \\
\hline & $>1$ year & $160(38.1)$ & 05 (13.5) & $28(65.1)$ & \\
\hline & Never & $00(0.0)$ & $00(0.0)$ & $00(0.0)$ & \\
\hline
\end{tabular}

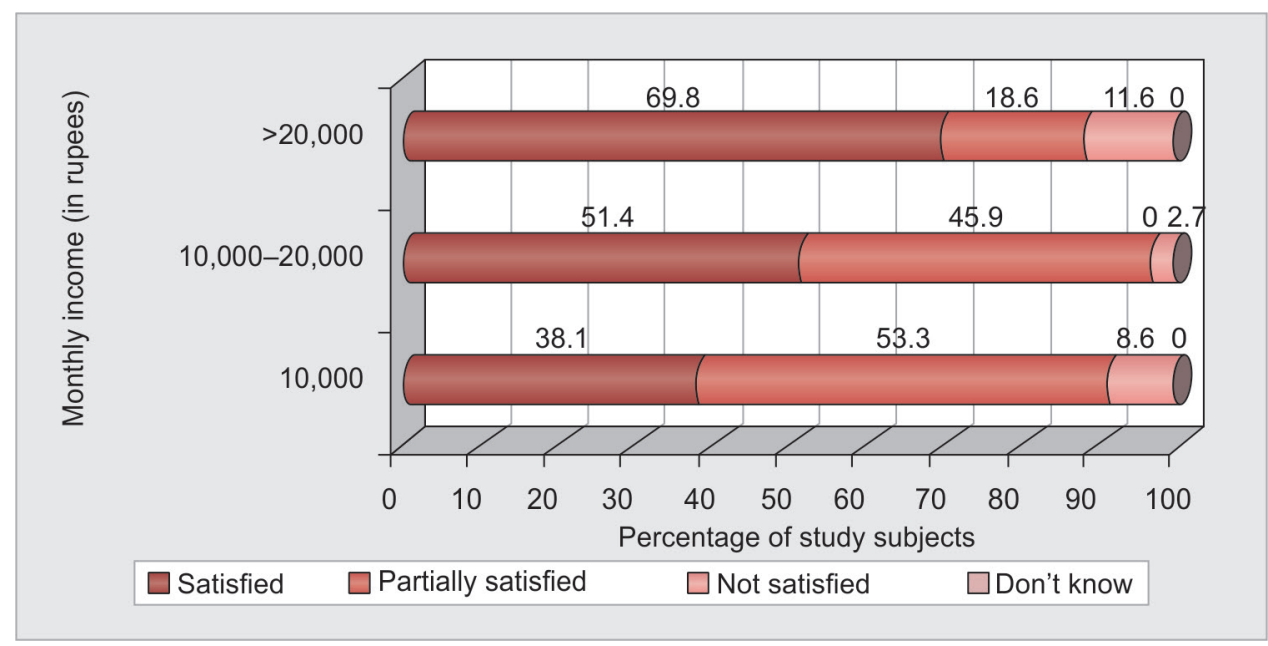

Graph 2: Subjects' satisfaction with denture and oral hygiene across income groups $(n=500)$

with decrease in monthly income. Nearly $65 \%$ of study subjects in more than Rs. 20,000 per month income group told that they never use any mouth rinse. In Rs. 10,000 to Rs. 20,000 per month income group, 20 (54.1\%) responded that their dentures should be replaced only when they are broken, become loose, or if lost. Subjects in the less than Rs. 10,000 per month income group were more regular and frequent in their follow-up visits to the dentist when compared with the other groups. The majority of subjects were partially satisfied in less than Rs. 10,000 per month income group; on the contrary, $51.4 \%$ of the subjects were satisfied in Rs. 10,000 to 20,000 and $69.8 \%$ of the subjects in more than Rs. 20,000 per month income groups $\left(\chi^{2}=\right.$ $36.033, \mathrm{p}<0.001)$ as presented in Graph 2.

\section{DISCUSSION}

This study describes a detailed patient behavior on denture cleansing regimens. The negative impact of poor denture hygiene among older adults is an important public health issue. ${ }^{4}$ Despite the fact that denture hygiene education is the utmost important part of denture therapy, most elderly patients are not sufficiently informed and periodically recalled to review denture care. Findings from this study indicated that the denture hygiene knowledge and practices were significantly associated with gender, level of education, and income of the denture wearers.

The results showed that a total of $195(39 \%)$ subjects comprising $39.5 \%$ males and $38.5 \%$ females were wearing the same dentures for more than 5 years. Peracini et $\mathrm{al}^{23}$ reported that $62.26 \%$ of their respondents had been using the same complete denture for over 5 years; there is also a report of most patients wearing their dentures for 20 years. ${ }^{30}$ There is another report wherein $30 \%$ of the subjects were using their removable partial dentures for more than 10 years. The reason for such prolonged use of dentures may be due to a variable level of education of denture wearers, socioeconomic level, and individual's access to dental care.

Previous studies ${ }^{21,31}$ have reported that the majority of denture wearers do not know how to clean their 
dentures because they have never received instructions from their dentist. In this study, $10.2 \%$ subjects reported never having been advised by their dentists as to how to clean their dentures. Contradictory results were obtained by Peracini et al, ${ }^{23}$ Dikbas et $\mathrm{al}^{31}$ Hoad-Reddick et al, ${ }^{24}$ and Marchini et $\mathrm{al}^{26}$ who found that $51.89,82.9,86.3$, and $77.5 \%$ of subjects respectively, were never advised. A significant difference was found between the high-income group (>Rs. 20,000) when compared with the other groups as all $(100 \%)$ subjects reported having received instructions for cleaning their dentures. The dentists also show a negative attitude toward disseminating proper instructions to their patients. In a previous study conducted in Jabalpur, $48 \%$ of the dentists strongly agreed that explaining denture hygiene instructions to the elderly can be very time-consuming and it is of no use to provide the elderly with denture hygiene maintenance instructions as they decline to follow. ${ }^{32}$ The responsibility of dissemination of denture care instructions falls solely on the dentist. This part was efficiently completed by this study group, as it was evident in most of the elderly subjects' higher knowledge scores. The reason for this may be due to the study setting; which was a postgraduate teaching institute where there are set protocols in denture patients care and after-care, and all the dentists working here are under supervision of a senior faculty member unlike a private dental practitioner.

In this study, all subjects (100\%) used brushing (mechanical method) for denture cleansing. A review of literature shows that percentage of subjects using mechanical methods for denture cleansing varied from a high of $97,{ }^{33} 86,{ }^{34} 80.1,{ }^{30} 79.7,{ }^{26}$ to a low of $57.1^{25}$ and $40.59 .{ }^{31}$ The current study reports that $45.8 \%$ of the subjects used tap water along with a toothbrush to clean their dentures. In a similar study by Veres et $\mathrm{al}^{35} 63 \%$ subjects used tap water to clean their dentures and according to the same author, brushing with only tap water without any cleansing agent was quite common. Brushing with a dentifrice was the method of choice by $84.91 \%$ of the subjects to clean their dentures as reported in a previous study. ${ }^{23}$ The use of toothpaste in denture cleansing is attributed to its familiarity, simple use, and cost-effectiveness. However, studies have claimed that improper brushing along with a dentifrice can damage the denture base material due to its abrasive potential. ${ }^{31}$ Only $11.4 \%$ of the subjects in this study reported immersion of their dentures in a commercially available denture cleanser. Comparable results were obtained in a previous study where $58.49 \%$ of subjects immerse their dentures in a chemical solution. ${ }^{23}$ Chemical cleansing agents mainly comprised cleansing tablets and sodium hypochlorite solution. This disparity in the percentage of subjects using the chemical cleansing agents may be due to disadvantages like bleaching effect on acrylic resins and corrosion of metallic components of the dentures. ${ }^{36}$ The use of chemical solutions for denture immersion is less frequent than manual brushing methods of cleaning. ${ }^{26}$

Lack of denture hygiene is one of the main etiological factors causing the inflammation of oral mucosa of the edentulous patients. ${ }^{13}$ Denture hygiene is directly related to the frequency of denture cleansing. This study reported that $53.2 \%$ of the subjects clean their dentures twice a day followed by $20.4 \%$ subjects to clean their dentures at least once a day. However, according to Pietrokovski et $\mathrm{al}_{1} 37 \mathrm{96} \%$ of the subjects reported cleaning their dentures twice a day. This study also established that a statistically significant relationship between the increase in the frequency of denture cleansing practices was observed as the educational level increased. The frequency of denture cleansing was significantly higher in males than females. The result of our studies was in line with some of the previous studies, where a higher rate of denture stomatitis and traumatic ulcers was reported among females than among males due to reduced frequency of denture cleaning. ${ }^{17}$ The variation among genders may be due to their lack of awareness, motivation, and strict adherence to denture care instructions.

Elderly denture wearers are prone to suffer from one or more oral mucosal lesions, such as denture stomatitis, burning mouth syndrome, angular cheilitis, candidal secondary infections, and many other mucosal lesions. Denture care instructions to denture patients should also include instructions to clean the soft tissues of the oral cavity. In the present study, $52.8 \%$ of the subjects reported brushing their tongue and hard palate similar to the previous study where $49.06 \%$ reported doing the same. ${ }^{23}$ Lack of denture hygiene leads to foul smell/ bad breath, oral mucosal lesions, inability to eat satisfactorily, and the difficulty in articulation. All these problems diminish the self-esteem and confidence of the denture wearers.

The present study showed that $13.2 \%$ of the subjects wore the dentures day and night. Higher percentage of the subjects sleeping with dentures is reported in previous studies where $41.5 \%{ }^{31}$ and $64 \%{ }^{38}$ of subjects respectively, did not remove their dentures at bedtime. Baran and Nalçaci ${ }^{17}$ also showed that $55.2 \%$ of subjects slept with their dentures. Marcus et a ${ }^{39}$ found that nearly one-third of the participants of their study slept with both dentures, and $12 \%$ slept with the lower denture only. Veres et $\mathrm{al}^{35}$ showed that $49 \%$ of the subjects wore their dentures continuously. This study also demonstrated the statistically significant difference in gender where the practice of sleeping wearing the dentures was more among males. The reason for wearing the dentures overnight may be because of the misinterpretation of their dentist's instructions to wear them overnight during initial stages 
of denture delivery to get them accustomed to the new dentures or to prevent embarrassment during social contacts to their peers.

The method of dentures storage when not in use or during the night was also varied. Ideally, immersion in plain water was followed by $64.8 \%$ of the subjects followed by $25.6 \%$ subjects wrapping it in a piece of cloth. There is a statistically significant difference between genders where $9.6 \%$ of the female subjects stored in the dentures in a plastic bag and $4.6 \%$ of the female subjects left the denture out in the air. These observations are far from the dentist's recommendations. This may be due to the lack of adequate denture hygiene instructions by the dentists leading to patients making their own interpretations or following the advice of their friends, pharmacists, media, and the internet.

The limitations of this study were that the study selected the patients attending one university hospital. Second, the knowledge and practices of denture hygiene should have been compared with the cleanliness of the dentures and the status of the denture-bearing soft tissues. Hence, further research is suggested for a thorough understanding of denture hygiene, attitude of denture wearers, and soft tissue changes.

\section{CONCLUSION}

Concluding within the limitations of this study, the majority of the denture wearers have limited knowledge of denture cleansing and oral hygiene practices. Hygiene habits and practices may not always present a positive correlation with the gender, educational level, and income of the subjects. Patients should be motivated and instructed by the dentists about denture cleansing methods, materials, and the harmful effects of overnight wearing and accumulation of microbial plaque and debris on the denture and mucosal surfaces. Periodic recall for evaluation of denture and mucosal surfaces along with reinforcement of denture hygiene instructions will go a long way in helping the patients reap maximum benefits out of their prostheses.

\section{REFERENCES}

1. Deogade SC, Vinay S, Naidu S. Dental prosthetic status and prosthetic needs of institutionalised elderly population in oldage homes of Jabalpur city, Madhya Pradesh, India. J Indian Prosthodont Soc 2013 Dec;13(4):587-592.

2. Dosumu OO, Denloye OO. Pattern of permanent tooth loss in Nigerian children and their prosthetic replacement. Afr J Med Sci 1999 Mar-Jun;28(1-2):31-33.

3. Mersel A, Babayof I, Rosin A. Oral health needs of elderly short-term patients in a geriatric department of general hospital. Spec Care Dentist 2000 Mar-Apr;20(2):72-74.

4. Petersen PE, Yamamoto T. Improving the oral health of older people: the approach of the WHO Global Oral
Health Programme. Community Dent Oral Epidemiol 2005 Apr;33(2):81-92.

5. Nalcaci R, Erdemir EO, Baran I. Evaluation of the oral health status of the people aged 65 years and over living in near rural district of Middle Anatolia, Turkey. Arch Gerontol Geriatr 2007 Jul-Aug;45(1):55-64.

6. Olusile AO, Esan TA. Pattern of demand of removable partial dentures in Ile-Ife. Niger J Health Sci 2002;2:6-8.

7. Ogunrinde TJ, Ajayi DM, Dosumu OO. Causes and pattern of fracture of acrylic denture among patients seen in a Nigerian teaching hospital. Afr J Med Sci 2007 Dec;36(4):365-369.

8. Douglass CW, Gammon MD, Atwood DA. Need and effective demand for prosthodontic treatment. J Prosthet Dent 1988 Jan;59(1):94-99.

9. Patel IB, Madan G, Patel B, Solanki K, Chavda R. Behaviours and hygiene habits of a sample population of complete denture wearers in Ahmedabad. J Int Oral Health 2012 May-Aug;4(2):29-38.

10. Cakan U, Yuzbasioglu E, Kurt H, Kara HB, Turunç R, Akbulut A, Aydin KC. Assessment of hygiene habits and attitudes among removable partial denture wearers in a university hospital. Niger J Clin Pract 2015 Jul-Aug;18(4):511-515.

11. Gendreau L, Loewy ZG. Epidemiology and etiology of denture stomatitis. J Prosthodont 2011 Jun;20(4):251-260.

12. Russell SL, Boylan RJ, Kaslick RS, Scannapieco FA, Katz RV. Respiratory pathogen colonization of the dental plaque of institutionalized elders. Spec Care Dentist 1999 May-Jun;19(3): 128-134.

13. Abelson DC. Denture plaque and denture cleansers: review of the literature. Gerodontics 1985 Oct;1(5):202-206.

14. Manderson RD, Ettinger RL. Dental status of the institutionalized elderly population of Edinburgh. Community Dent Oral Epidemiol 1975 Jun;3(3):100-107.

15. Axe AS, Varghese R, Bosma M, Kitson N, Bradshaw DJ. Dental health professional recommendation and consumer habits in denture cleansing. J Prosthet Dent 2016 Feb;115(2):183-188.

16. Apratim A, Shah SS, Sinha M, Agrawal M, Chhaparia N, Abubakkar A. Denture hygiene habits among elderly patients wearing complete dentures. J Contemp Dent Pract 2013 Nov;14(6):1161-1164.

17. Baran I, Nalçaci R. Self-reported denture hygiene habits and oral tissue conditions of complete denture wearers. Arch Gerontol Geriatr 2009 Sep-Oct;49(2):237-241.

18. Barreiro DM, Scheid PA, May LG, Unfer B, Braun KO. Evaluation of procedures employed for the maintenance of removable dentures in elderly individuals. Oral Health Prev Dent 2009 Jan;7(3):243-249.

19. Chowdhary R, Chandraker NK. Clinical survey of denture care in denture wearing edentulous patients of Indian population. Geriatr Gerontol Int 2011 Apr;11(2):191-195.

20. Murtomaa H, Könönen M, Laine P. Age and maintenance of removable dentures in Finland. J Oral Rehabil 1992 Mar;19(2):123-128.

21. Jagger DC, Harrison A. Denture cleansing the best approach. Br Dent J 1995 Jun;178(11):413-417.

22. Maeda Y, Idoji S, Mori T, Naito K, Emura I, Seya N, Okada M, Nokubi T, Okuno Y, Makishima T. Problems of denture wearers regarding denture cleaning. J Osaka Univ Dent Sch 1990 Dec;30:120-124.

23. Peracini A, de Andrade IM, Paranhos HFO, da Silva CHL, de Souza RF. Behaviors and hygiene habits of complete denture wearers. Braz Dent J 2010;21(3):247-252. 
24. Hoad-Reddick G, Grant AA, Griffiths CS. Investigation into the cleanliness of dentures in an elderly population. J Prosthet Dent 1990 Jul;64(1):48-52.

25. Kulak-Ozkan Y, Kazazoglu E, Arikan A. Oral hygiene habits, denture cleanliness, presence of yeasts and stomatitis in elderly people. J Oral Rehabil 2002 Mar;29(3):300-304.

26. Marchini L, Tamashiro E, Nascimento DF, Cunha VP. Selfreported denture hygiene of a sample of edentulous attendees at a university dental clinic and the relationship to the condition of the oral tissues. Gerodontology 2004 Dec;21(4): 226-228.

27. Doğan BG, Gökalp S. Tooth loss and edentulism in the Turkish elderly. Arch Gerontol Geriatr 2012 Mar-Apr;54(2):e162-e166.

28. Lal S, Paul D, Vashisht BM. Editorial-national oral health care programme (NOHCP) implementation strategies. Indian J Community Med 2004 Jan-Mar;29(1):1-10.

29. SPSS Inc. SPSS 21.0 for Windows. Chicago (IL): SPSS Inc; 2005.

30. Coelho CM, Sousa YT, Daré AM. Denture-related oral mucosal lesions in a Brazilian school of dentistry. J Oral Rehabil 2004 Feb;31(2):135-139.

31. Dikbas I, Koksal T, Calikkocaoglu S. Investigation of the cleanliness of dentures in a university hospital. Int J Prosthodont 2006 May-Jun;19(3):294-298.

32. Suresan V, Mantri S, Deogade S, Sumathi K, Panday P, Galav A, Mishra K. Denture hygiene knowledge, attitudes, and practices toward patient education in denture care among dental practitioners of Jabalpur city, Madhya Pradesh, India. J Indian Prosthodont Soc 2016 Jan-Mar;16(1):30-35.

33. Jeganathan S, Payne JA, Thean HP. Denture stomatitis in an elderly edentulous Asian population. J Oral Rehabil 1997 Jun;24(6):468-472.

34. Polyzois GL. Denture cleansing habits. A survey. Aust Dent J 1983 Jun;28(3):171-173.

35. Veres EM, Wolfaardt JF, Hnizdo E. Denture cleansers: Part III - a survey of materials and methods employed by denture wearers. J Dent Assoc S Afr 1985 Oct;40(10):591-594.

36. Fernandes FH, Orsi IA, Villabona CA. Effects of the peracetic acid and sodium hypochlorite on the colour stability and surface roughness of the denture base acrylic resins polymerised by microwave and water bath methods. Gerodontology 2013 Mar;30(1):18-25.

37. Pietrokovski J, Azuelos J, Tau S, Mostavoy R. Oral findings in elderly nursing home residents in selected countries. Oral hygiene conditions and plaque accumulation on denture surfaces. J Prosthet Dent 1995 Feb;73(2):136-141.

38. de Castellucci Barbosa L, Ferreira MR, de Carvalho Calabrich CF, Viana AC, de Lemos MC, de Lauria RA. Edentulous patients' knowledge of dental hygiene and care of prostheses. Gerodontology 2008 Jun;25(2):99-106.

39. Marcus PA, Joshi A, Jones JA, Morgano SM. Complete edentulism and denture use for elders in New England. J Prosthet Dent 1996 Sep;76(3):260-266. 